\title{
SISTEM CERDAS PEMANTAU KENYAMANAN RUANG KELAS BERBASIS INTERNET OF THINGS (IoT) MENGGUNAKAN METODE K-MEANS PADA PLATFORM THINGSPEAK
}

\author{
Usep Tatang Suryadi ${ }^{*}$,Sri Saraswati ${ }^{\# 2}$ \\ Program Studi Teknik Informatika, STMIK Subang*1 \\ Program Studi Teknik Informatika, STMIK Subang ${ }^{\# 2}$ \\ e-mail: ugie89@gmail.com ${ }^{* 1}$, srisaraswati2@gmail.com ${ }^{\# 2}$
}

\begin{abstract}
Abstrak
Monitoring kenyamanan ruang kelas dalam rentang waktu tertentu bagi ruangan adalah salah satu yang cukup penting untuk dilakukan. Peningkatan kelembaban, suhu, suara, cahaya akan mempengaruhi konsetrasi belajar mengajar. Dalam perancangan sistem ini, penulis bermaksud untuk merancang sistem monitoring kenyamanan ruang kelas berbasis internet of things (IoT) supaya jangkauannya lebih luas.

Penelitian ini bertujuan untuk mengelompokan data kedalam sebuah cluster dengan menggunakan metode Data Mining algoritma K-means Clustering. Data dikelompokan berdasarkan kemiripan data tersebut sehingga data dengan karakteristik yang sama akan berada dalam satu cluster. Atribut yang digunakan adalah kelembaban, suhu, suara dan cahaya. Hasil K-Means Clustering yang diperoleh ada 3 kelompok, pusat cluster dengan cluster $1=47,76 ; 26,07 ; 61 ; 92 ; 3602$ cluster $2=58 ; 29 ; 59,5 ; 502$ dan cluster $3=$ $60 ; 30,25 ; 58,75 ; 769,75$. Cluster dengan nilai paling tinggi adalah cluster tiga. Iterasi clustering data terjadi sebanyak 4 kali iterasi.

Mekanisme yang diterapkan dalam sistem ini yaitu sistem monitoring kenyamanan ruang kelas. Sistem bertugas mengambil dan mengkalkulasi data fisik berupa kelembaban, suhu, suara, cahaya melalui sensor menjadi informasi pada ruangan yang dipantau menggunakan mikrokontroler Arduino Mega2560 dan sensor DHT11, LDR, Kondensor yang terhubung dengan thingspeak. Algoritma K-Means dapat melakukan klasterisasi dengan baik pada system yang dibangun.
\end{abstract}

Kata kunci: Arduino Mega 2560, DHT11, ESP8266, Internet Of Things (IoT), K-means, Kondensor, LDR, Mikrokontroler, Ruang Kelas, Sensor, Sistem Pemantau.

\begin{abstract}
Monitoring the comfort of classrooms within a certain timeframe for the room is one that is quite important to do. Increased humidity, temperature, sound, the light will affect the concentration of teaching and learning. In designing this system, the author intends to design a convenience monitoring system based on the internet of things (IoT) so that its scope is wider.

This study aims to group data into clusters using the Data Mining method, the K-means Clustering algorithm. Data is grouped based on this similarity data so that data with the same characteristics will be in one cluster. The attributes used are humidity, temperature, sound, and light. The results of K-Means Clustering obtained were 3 groups, cluster center with cluster $1=47.76 ; 26.07 ; 61 ; 92 ; 3602$ clusters 2 $=58 ; 29 ; 59.5 ; 502$ and cluster $3=60 ; 30.25 ; 58,75 ; 769,75$. The cluster with the highest value is cluster three. Iteration of data grouping occurs 4 times iteration.

The system implemented in this system is a classroom comfort monitoring system. The retrieval system takes and calculates physical data to form humidity, temperature, sound, light through sensors into information in the room that is monitored using the Arduino Mega2560 microcontroller and DHT11, LDR, Condenser sensors that are connected to the things that speak. K-means algorithm can do a good clustering on the system being built.
\end{abstract}

Keywords: Arduino Mega 2560, DHT11, ESP8266, Internet of Things (IoT), K-means, Condenser, LDR, Microcontroller, Classroom, Sensor, Monitoring System. 


\section{Pendahuluan}

Dalam proses belajar mengajar di ruang kelas khususnya pada kampus STMIK Subang, mahasiswa membutuhkan tempat atau ruang kelas yang nyaman agar dapat berkonsentrasi pada suatu mata kuliah yang sedang dipelajarinya. Salah satu faktor kenyamanan dalam proses belajar mengajar pada suatu ruang kelas ditentukan oleh keadaan lingkungan tempat dimana proses tersebut dilakukan. Suhu dan kelembapan udara ruangan dinilai sangat mempengaruhi kelancaran proses belajar mengajar. Untuk itu pentingnya menjaga dan memantau kondisi ruang kelas.

Kenyamanan merupakan bagian dari salah satu sasaran karya arsitektur, definisi kenyamanan merupakan interaksi dan reaksi manusia terhadap lingkungan yang bebas dari rasa negative dan bersifat subjektif. Kenyamanan terdiri atas kenyamanan psikis dan kenyamanan fisik. Kenyamanan psikis yaitu kenyamanan kejiwaan (rasa, aman, tenang, gembira dan lain - lain) yang terukur secara subjektif (kualitatif). Sedangkan kenyamanan fisik dapat terukur secara obyektif (kuantitatif) yang meliputi kenyamanan spasial, visual, auditorial dan termal. Adapun istilah - istilah kenyamanan termal yang paling bias sampai yang tidak bias menurut Sugini, adalah dari gerah, nyaman, panas, dingin, sejuk dan pengap. [1]

Seiring perkembangan teknologi saat ini sangat pesat, zaman sudah memasuki Internet of Things (IoT) dimana seluruh objek yang terhubung dengan komputer dapat bekerja menggunakan koneksi internet yang terus berlangsung, terus terhubung dan dapat melakukan identifikasi serta dapat melakukan aktifitas sesuai dengan yang direncanakan antara perangkat yang satu dengan yang lainnya. Dengan begitu kenyamanan ruang kelas ini akan di pantau menggunakan mikrokontroler yang terhubung dengan Internet.

Menurut Keputusan Menteri Kesehatan Republik Indonesia Nomor 1405/Menkes/SK/XI/2002 mengenai Persyaratan Kesehatan Lingkungan Kerja Perkantoran dan Industri, bahwa suhu berkisar 180C - 280C dan kelembapan udara 40\% - 60\%. Seperti halnya pada proses pemantauan ruang kelas ini data yang didapat dari alat mikrokontroler yang sudah di buat akan di olah menggunakan Data Mining dengan metode algoritma $K$-Means Clustering.

Maka dari itu, pada penelitian kali ini akan mengimplementasikan "Sistem Cerdas Pemantau Kenyamanan Ruang Kelas Berbasis Intenet Of Things (IoT) menggunakan Metode K-Means pada Platform Thingspeak" yang digunakan untuk membantu pihak BAAK STMIK Subang sebagai bahan pemantau ruang kelas STMIK Subang agar dapat mengetahui update kenyamanan ruang kelas

\section{Tinjauan Pustaka}

Data Mining adalah sebuah proses penyelesaian masalah dengan menganalisis data yang sudah terekam dalam database [2]. Teknik Data Mining sendiri terdiri dari beberapa tahapan dan memiliki beberapa metode dalam penyelesaian masalah data, mulai dari klasifikasi, klasterisasi, forecasting dan sebagainya. Metode Klasterisasi (Clustering) adalah salah satu metode klasterisasi yang klasik, yang mana pertama kita tentukan berapa banyak klaster yang diinginkan yang artinya jumlah K-nya dan seterusnya sampai akhirnya mendapatkan hasil klaterisasi data. [2]

Mikrokontroler adalah sistem komputer yang seluruh atau sebagian besar elemennya dikemas dalam satu chip IC, sehingga sering disebut single chip microcomputer. Mikrokontroler merupakan sistem komputer yang mempunyai salah satu atau beberapa tugas yang sangat spesifik. [3]

Secara umum Internet Of Things merupakan sebuah konsep yang bertujuan untuk memperluas manfaat dari konektivitas Internet yang tersambung secara terus - menerus. Yang memungkinkan daya pengendalian, komunikasi, kerja sama dengan berbagai perangkat keras, berbagai data, memvirtualisasikan segala hal nyata ke dalam bentuk Internet, melalui jaringan Internet atau disebut juga M2M (Machine to Maachine). [4]

Dalam penelitian Parma Dkk, alat pendeteksi kenyamanan kelas menggunakan 3 sensor (cahaya, suhu dan suara) beserta feedback (lampu, AC dan alarm) yang menyala dan mati secara otomatis [5]. Penelitian selanjutnya oleh Dhika dan Destiawati menjelaskan pentingnya pemanfaatan teknologi dalam ruang kelas belajar mengajar dikarenakan kebutuhan saat ini semakin meningkat dengan perkembangan zaman. 
Dengan hasil membuat pembelajar dapat lebih kondusif lagi, sehingga paradigma baru dunia pendidikan dengan ruang kelas IoT dapat membantu dan mendukung mahasiswa lebih mengenal perkembangan teknologi yang kini telah berkembang [6]. Pada penelitian ini akan menggunakan metode $K$-Means dengan berbasis Internet of Things (IoT) sehingga menjadi keunikan tersendiri. Dalam aktivitas klasterisasi, penggunaan metode $K$-Means Clustering telah digunakan untuk berbagai macam keperluan pemberian klasterisasi, seperti Menentukan kelas kelompok bimbingan belajar tambahan yang dilakukan oleh Mardalius. [7]

\section{Analisa dan Pembahasan}

Urutan proses clustering dengan algoritma K-means untuk dapat melakukan pengelompokan data menjadi beberapa cluster adalah sebagai berikut :

1. Tentukan nilai K sebagai jumlah cluster yang diinginkan. Dalam penelitian ini data-data yang ada akan dikelompokan menjadi tiga cluster.

2. Tentukan titik pusat awal dari setiap cluster. Dalam penelitian ini titik pusat awal ditentukan secara random dan titik pusat dari setiap cluster dapat dilihat pada tabel.

Inisial data titik pusat awal (K) diambil secara random dari data, diantaranya : data ke 3, 13 dan 20.

Tabel 3.1 Titik Pusat Awal Setiap Cluster

\begin{tabular}{|c|c|c|c|c|c|}
\hline $\begin{array}{c}\text { Titik Pusat } \\
\text { Awal }\end{array}$ & Nama Ruang & Kelembaban & Suhu & Suara & Cahaya \\
\hline Cluster 1 & Ruang 1 C & 49 & 25 & 60 & 269 \\
\hline Cluster 2 & Ruang 1 M & 52 & 27 & 61 & 344 \\
\hline Cluster 3 & Ruang 2 T & 61 & 30 & 59 & 962 \\
\hline
\end{tabular}

3. Menghitung jarak setiap data ke titik pusat cluster atau centroid awal antara objek ke centroid dengan perhitungan jarak Euclidean.

4. Tempatkan setiap data pada cluster. Dalam penelitian ini digunakan metode hard k-means untuk mengalokasikan setiap data ke dalam suatu cluster, sehingga data akan dimasukan dalam suatu cluster yang memiliki jarak paling dekat dengan titik pusat dari setiap cluster. Untuk mengetahui cluster mana yang paling dekat dengan data, maka perlu dihitung jarak setiap data dengan titik pusat setiap cluster. 
Tabel 3.2 Hasil Perhitungan Manual ke-1

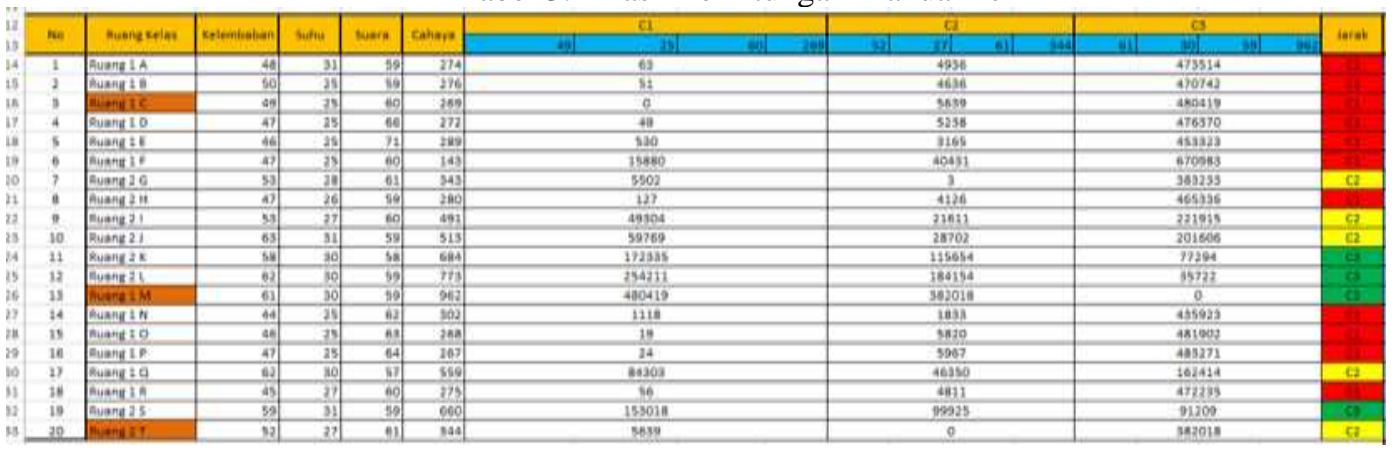

5. Hitung rata-rata setiap cluster untuk menentukan centroid baru berdasarkan data yang tergabung didalamnya. Cluster 1 : ada 11 data yang tergabung, dapat dilihat pada Tabel 3.6

Menghitung fungsi keanggotaan untuk harga sebagai berikut:

Tabel 3.3 Centroid Baru Pada Iterasi ke- 1

\begin{tabular}{|c|r|r|r|r|}
\hline \multirow{2}{*}{ No } & \multicolumn{5}{|c|}{ Cluster 1 } \\
\cline { 2 - 5 } & Kelembaban & Suhu & Suara & Cahaya \\
\hline 1 & 48 & 31 & 59 & 274 \\
\hline 2 & 50 & 25 & 59 & 276 \\
\hline 3 & 49 & 25 & 60 & 269 \\
\hline 4 & 47 & 25 & 66 & 272 \\
\hline 5 & 46 & 25 & 71 & 289 \\
\hline 6 & 47 & 25 & 60 & 143 \\
\hline 8 & 47 & 26 & 59 & 280 \\
\hline 14 & 44 & 25 & 62 & 302 \\
\hline 15 & 46 & 25 & 63 & 268 \\
\hline 16 & 47 & 25 & 64 & 267 \\
\hline 18 & 45 & 27 & 60 & 275 \\
\hline Jumlah & Jumlah & Jumlah & Jumlah & Jumlah \\
\hline & 516 & 284 & 683 & 2915 \\
\hline Rata-rata & 46.90909 & 25.81818 & 62.09091 & 265 \\
\hline
\end{tabular}

Cluster 2 : ada 5 data yang tergabung, dapat dilihat pada Tabel 3.6

Tabel 3.4 Centroid Baru Pada Iterasi ke-1

\begin{tabular}{|c|r|r|r|r|}
\hline \multirow{2}{*}{ No } & \multicolumn{5}{|c|}{ Cluster 2 } \\
\cline { 2 - 5 } & Kelembaban & \multicolumn{1}{|c|}{ Suhu } & \multicolumn{1}{c|}{ Suara } & Cahaya \\
\hline 7 & 53 & 28 & 61 & 343 \\
\hline 9 & 53 & 27 & 60 & 491 \\
\hline 10 & 63 & 31 & 59 & 513 \\
\hline
\end{tabular}




\begin{tabular}{|c|c|c|c|c|}
\hline \multirow{2}{*}{ No } & \multicolumn{4}{|c|}{ Cluster 2} \\
\hline & Kelembaban & Suhu & Suara & Cahaya \\
\hline 17 & 62 & 30 & 57 & 559 \\
\hline 20 & 52 & 27 & 61 & 344 \\
\hline Jumlah & Jumlah & Jumlah & Jumlah & Jumlah \\
\hline 5 & 283 & 143 & 298 & 2250 \\
\hline Rata-rata & 56.6 & 28.6 & 59.6 & 450 \\
\hline
\end{tabular}

Cluster 3 : ada 4 data yang tergabung didalamnya, dapat dilihat pada Tabel 3.6

Tabel 3.5 Centroid Baru Pada Iterasi ke -1

\begin{tabular}{|c|r|r|r|r|}
\hline \multirow{2}{*}{ No } & \multicolumn{5}{|c|}{ Cluster 3} \\
\cline { 2 - 5 } & Kelembaban & \multicolumn{1}{c|}{ Suhu } & \multicolumn{1}{c|}{ Suara } & Cahaya \\
\hline 11 & 58 & 30 & 58 & 684 \\
\hline 12 & 62 & 30 & 59 & 773 \\
\hline 13 & 61 & 30 & 59 & 963 \\
\hline 19 & 59 & 31 & 59 & 660 \\
\hline Jumlah & Jumlah & Jumlah & Jumlah & Jumlah \\
\hline & 240 & 121 & 235 & 3080 \\
\hline Rata-rata & 60 & 30.25 & 58.75 & 770 \\
\hline
\end{tabular}

6. Setelah menghitung rata-rata untuk menentukan centroid baru maka hitung kembali ke Step 3, apabila masih ada data yang berpindah cluster atau apabila ada perubahan nilai centroid.

Hasil perhitungan manual ke-2 didapat hasil jarak terdekat sebagai berikut :

Tabel 3.6 Hasil perhitungan Manual ke-2

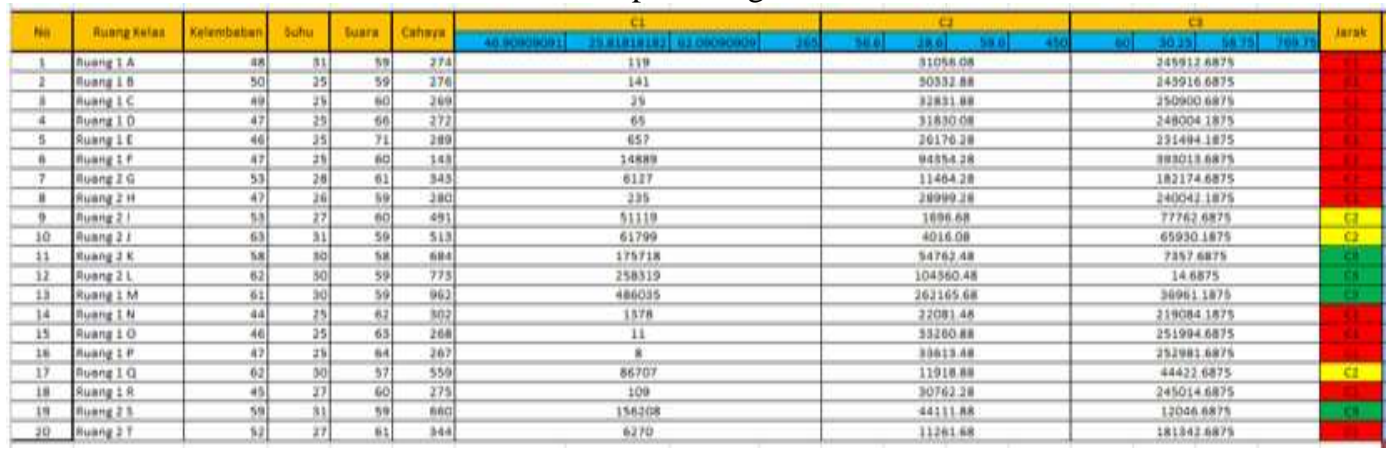

Hitung rata-rata setiap cluster untuk menentukan centroid baru berdasarkan data yang tergabung didalamnya.

Cluster 1 : ada 13 data yang tergabung

Tabel 3.7 Centroid Baru Iterasi ke -2

\begin{tabular}{|c|r|r|r|r|}
\hline \multirow{2}{*}{ No } & \multicolumn{5}{|c|}{ Cluster 1 } \\
\cline { 2 - 5 } & Kelembaban & \multicolumn{1}{|c|}{ Suhu } & \multicolumn{1}{l|}{ Suara } & Cahaya \\
\hline 1 & 48 & 31 & 59 & 274 \\
\hline 2 & 50 & 25 & 59 & 276 \\
\hline 3 & 49 & 25 & 60 & 269 \\
\hline
\end{tabular}




\begin{tabular}{|c|c|c|c|c|}
\hline \multirow{2}{*}{ No } & \multicolumn{4}{|c|}{ Cluster 1} \\
\hline & Kelembaban & Suhu & Suara & Cahaya \\
\hline 4 & 47 & 25 & 66 & 272 \\
\hline 5 & 46 & 25 & 71 & 289 \\
\hline 6 & 47 & 25 & 60 & 143 \\
\hline 7 & 53 & 28 & 61 & 343 \\
\hline 8 & 47 & 26 & 59 & 280 \\
\hline 14 & 44 & 25 & 62 & 302 \\
\hline 15 & 46 & 25 & 63 & 268 \\
\hline 16 & 47 & 25 & 64 & 267 \\
\hline 18 & 45 & 27 & 60 & 275 \\
\hline 20 & 52 & 27 & 61 & 344 \\
\hline Jumlah & Jumlah & Jumlah & Jumlah & Jumlah \\
\hline 13 & 621 & 339 & 805 & 3602 \\
\hline Rata-rata & 47.76923 & 26.07692 & 61.92308 & 277.0769 \\
\hline
\end{tabular}

Cluster 2 : ada 3 data yang tergabung

Tabel 3.8 Centroid Baru Iterasi ke -2

\begin{tabular}{|r|r|r|r|r|}
\hline \multirow{2}{*}{ No } & \multicolumn{5}{|c|}{ Cluster 2} \\
\cline { 2 - 6 } & Kelembaban & \multicolumn{1}{|c|}{ Suhu } & \multicolumn{1}{|c|}{ Suara } & Cahaya \\
\hline 9 & 53 & 27 & 60 & 491 \\
\hline 10 & 63 & 31 & 59 & 513 \\
\hline 17 & 62 & 30 & 57 & 559 \\
\hline Jumlah & Jumlah & Jumlah & Jumlah & Jumlah \\
\hline & 178 & 88 & 176 & 1563 \\
\hline Rata-rata & 59.33333 & 29.33333 & 58.66667 & 521 \\
\hline
\end{tabular}

Cluster 3 : ada 11 data yang tergabung

Tabel 3.9 Centroid Baru Iterasi ke -2

\begin{tabular}{|r|r|r|r|r|}
\hline \multirow{2}{*}{ No } & \multicolumn{5}{|c|}{ Cluster 3} \\
\cline { 2 - 6 } & Kelembaban & \multicolumn{1}{c|}{ Suhu } & \multicolumn{1}{c|}{ Suara } & Cahaya \\
\hline 11 & 58 & 30 & 58 & 684 \\
\hline 12 & 62 & 30 & 59 & 773 \\
\hline 13 & 61 & 30 & 59 & 962 \\
\hline 19 & 59 & 31 & 59 & 660 \\
\hline Jumlah & Jumlah & Jumlah & Jumlah & Jumlah \\
\hline & 240 & 121 & 235 & 3079 \\
\hline Rata-rata & 60 & 30.25 & 58.75 & 769.75 \\
\hline
\end{tabular}


Hasil perhitungan manual ke-3 didapat hasil jarak terdekat sebagai berikut:

Tabel 3.10 Hasil Perhitungan Manual ke-3

\begin{tabular}{|c|c|c|c|c|c|c|c|c|c|}
\hline No & Ruane Kelass & Kelembaban & Suhu & Suarta & Cahava & C1 & $\mathrm{Cl}^{-2}$ & a & \\
\hline & & & & 3000 & Canarya & 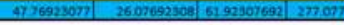 & 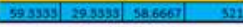 & \begin{tabular}{|l|l|l|l|}
60 & 3025 & 5875 & 76975 \\
\end{tabular} & \\
\hline 1 & Pluang $1 \mathrm{~A}$ & 48. & 31 & 59 & 274 & 42 & 61140.39393 & 245912.6875 & \\
\hline 2 & Ruang 1 18 & so & 25 & 59 & 276 & 16 & 60131 & 2439165875 & \\
\hline 3 & Ruane 1c & 49. & 25 & 60 & 269 & 72 & 63631.33333 & 2509006875 & \\
\hline 4 & Ruang 10 & 47 & 25 & 66 & 272 & 44 & 62225.66667 & 245004.1875 & \\
\hline 5 & Fuank 1E & 46 & 25 & 71 & 289 & 229 & 5417266657 & 2314941875 & \\
\hline 6 & fivang 17 & 47 & 25 & 60 & 143. & 17982 & 143056.6667 & 393013.6875 & \\
\hline 7 & Ruane 2G G & 53. & 28 & $6 !$ & 343 & 4378 & 31731.33333 & 182174.6875 & \\
\hline 8 & Pluang $2 \mathrm{H}$ & 47 & 26 & 59 & 280 & 18 & 58244.38333 & 2400421875 & \\
\hline 9 & Ruane 21 & 53 & 27 & 60 & 493 & 45795 & 947.33333333 & 777626875 & $c^{2}$ \\
\hline 10 & Ruanz 21 & 63 & 31 & 59 & 513 & 55924 & 80,33535333 & 659301875 & $c_{2}$ \\
\hline 13 & fivane $2 \mathrm{~K}$ & 58 & 30 & 58 & 634 & 165722 & 26571.66667 & 7357.6875 & \\
\hline 12 & fluang 21 & 62. & 30 & 59 & 773 & 246166 & 6351166667 & 14.6875 & a \\
\hline 13 & puare $1 \mathrm{M}$ & 6: & 90 & 59 & 962 & 469319 & 1944843333 & 369611875 & ca \\
\hline 14 & Auane $1 \mathrm{~N}$ & 44 & 25 & 62 & 302 & 637 & 48226 & 2190841875 & \\
\hline 15 & Ruane 10 & 46. & 25 & 63 & 268 & 88 & 64224.33333 & 251994.6875 & \\
\hline 16 & fivane 1P & 47 & 25 & 64 & 267 & 108 & 64715333353 & 2529816875 & \\
\hline 17 & fivans 10 & 62. & 30 & 57 & 559 & 79723 & 14543333333 & 44422.6875 & $c_{2}$ \\
\hline 18 & Ausone $1 R$ & 45 & 27 & 60 & 275 & 17 & 60728.66667 & 245014.6875 & \\
\hline 19 & fluang 25 & 59. & 31. & 59 & 660 & 146789 & 19324 & 120666875 & ca \\
\hline 20 & fluang $2 T$ & 52 & 27 & 61 & 344 & 4498 & 31393.66667 & 181342.6875 & $c_{1}$ \\
\hline
\end{tabular}

Hitung rata-rata setiap cluster untuk menentukan centroid baru berdasarkan data yang tergabung didalamnya

Cluster 1 : ada 13 data yang tergabung

Tabel 3.11 Centroid baru Iterasi ke 3

\begin{tabular}{|c|r|r|r|r|}
\hline \multirow{2}{*}{ No } & \multicolumn{5}{|c|}{ Cluster 1 } \\
\cline { 2 - 5 } & Kelembaban & \multicolumn{1}{|c|}{ Suhu } & \multicolumn{1}{l|}{ Suara } & Cahaya \\
\hline 1 & 48 & 31 & 59 & 274 \\
\hline 2 & 50 & 25 & 59 & 276 \\
\hline 3 & 49 & 25 & 60 & 269 \\
\hline 4 & 47 & 25 & 66 & 272 \\
\hline 5 & 46 & 25 & 71 & 289 \\
\hline 6 & 47 & 25 & 60 & 143 \\
\hline 7 & 53 & 28 & 61 & 343 \\
\hline 8 & 47 & 26 & 59 & 280 \\
\hline 14 & 44 & 25 & 62 & 302 \\
\hline 15 & 46 & 25 & 63 & 268 \\
\hline 16 & 47 & 25 & 64 & 267 \\
\hline 18 & 45 & 27 & 60 & 275 \\
\hline 20 & 52 & 27 & 61 & 344 \\
\hline Jumlah & Jumlah & Jumlah & Jumlah & Jumlah \\
\hline 13 & 621 & 339 & 805 & 3602 \\
\hline Rata-rata & 47.76923 & 26.07692 & 61.92308 & 277.0769 \\
\hline
\end{tabular}


Cluster 2 : ada 3 data yang tergabung

Tabel 3.12 Centroid Baru Iterasi ke 3

\begin{tabular}{|r|r|r|r|r|}
\hline \multirow{2}{*}{ No } & \multicolumn{5}{|c|}{ Cluster 2} \\
\cline { 2 - 6 } & Kelembaban & \multicolumn{1}{|c|}{ Suhu } & \multicolumn{1}{l|}{ Suara } & Cahaya \\
\hline 9 & 53 & 27 & 60 & 491 \\
\hline 10 & 63 & 31 & 59 & 513 \\
\hline 17 & 62 & 30 & 57 & 559 \\
\hline Jumlah & Jumlah & Jumlah & Jumlah & Jumlah \\
\hline 3 & 178 & 88 & 176 & 1563 \\
\hline Rata-rata & 59.33333 & 29.33333 & 58.66667 & 521 \\
\hline
\end{tabular}

Cluster 3 : ada 4 data yang tergabung

Tabel 3.13 Centroid Baru Iterasi ke-3

\begin{tabular}{|c|c|c|c|c|}
\hline \multirow{2}{*}{ No } & \multicolumn{4}{|c|}{ Cluster 3} \\
\hline & Kelembaban & Suhu & Suara & Cahaya \\
\hline 11 & 58 & 30 & 58 & 684 \\
\hline 12 & 62 & 30 & 59 & 773 \\
\hline 13 & 61 & 30 & 59 & 962 \\
\hline 19 & 59 & 31 & 59 & 660 \\
\hline Jumlah & Jumlah & Jumlah & Jumlah & Jumlah \\
\hline 4 & 240 & 121 & 235 & 3079 \\
\hline Rata-rata & 60 & 30.25 & 58.75 & 769.75 \\
\hline
\end{tabular}

Hasil perhitungan manual ke-4 didapat hasil jarak terdekat sebagai berikut :

Tabel 3.14 Hasil Perhitungan Manual ke 4

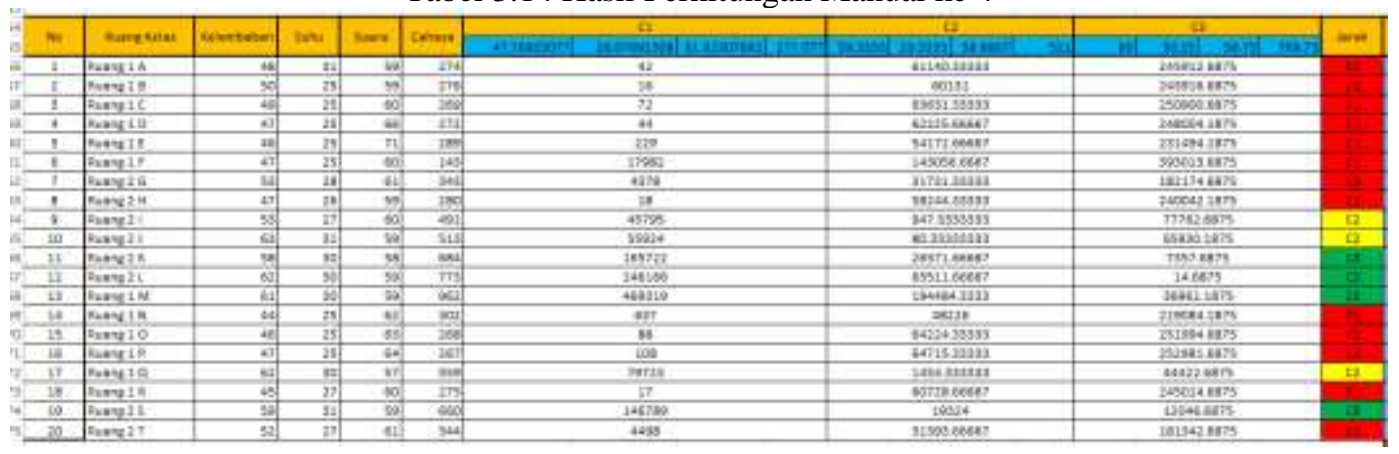

Setelah melakukan proses perhitungan manual iterasi clustering data yang terjadi sebanyak 4 kali iterasi. Pada iterasi ke-4 ini, titik pusat dari setiap cluster sudah tidak berubah dan tidak ada lagi data yang berpindah dari satu cluster ke cluster yang lain 


\subsection{Model Data}

Model data yang digunakan pada sistem ini yaitu Entity Relationship Diagram(ERD) yang menjelaskan hubungan antar data dalam basis data. Dalam sistem ini terdapat satu ERD yaitu data.

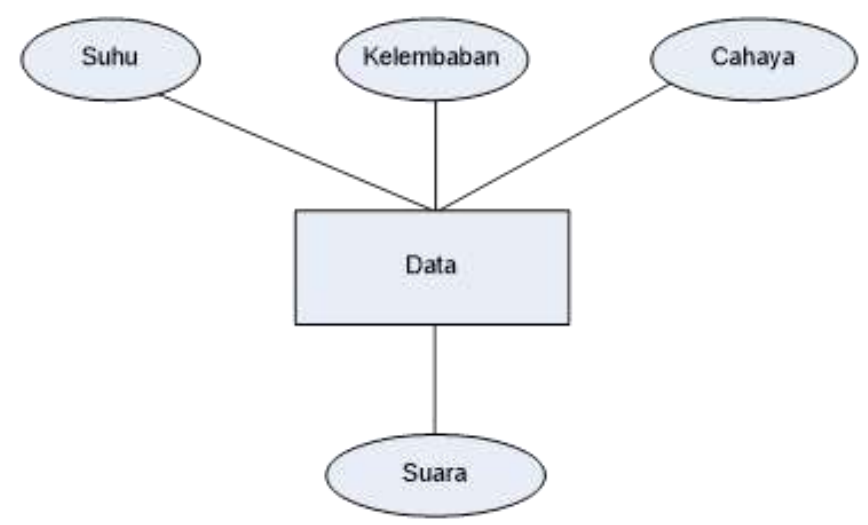

Gambar 3.2 Entity Diagram Monitoring ruang kelas

Penjelasan Entitas Diagram pada Gambar di atas menjelaskan bahwa Entitas Data memilik artibut suhu, kelembaban, suara, dan cahaya.

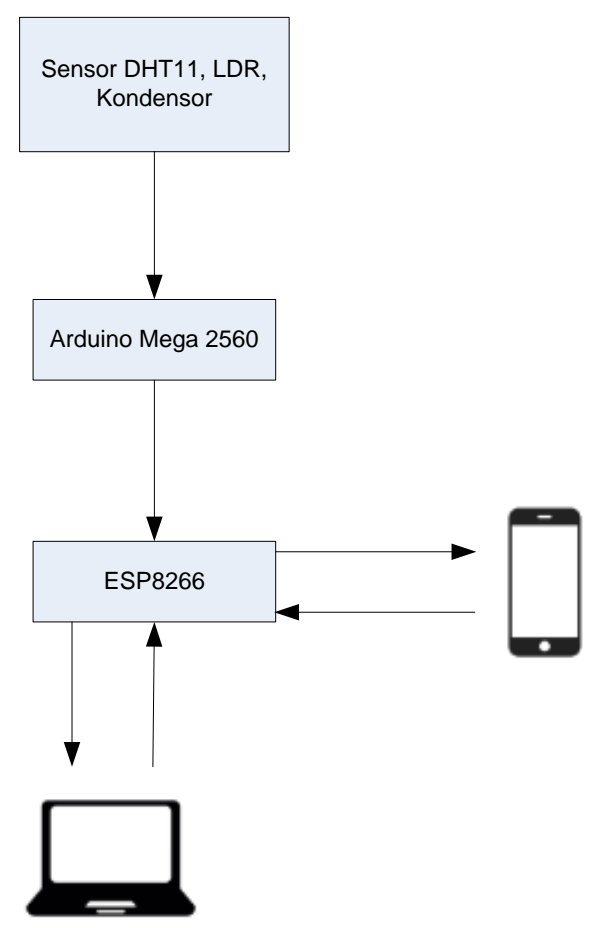

Gambar 3.5 Arsitektur jaringan komputer

Sistem monitoring ruang kelas yang dirancang menggunakan arsitektur jaringan komputer WAN point to point. Arsitektur jaringan yang dimaksud, diperlihatkan pada gambar di atas. 


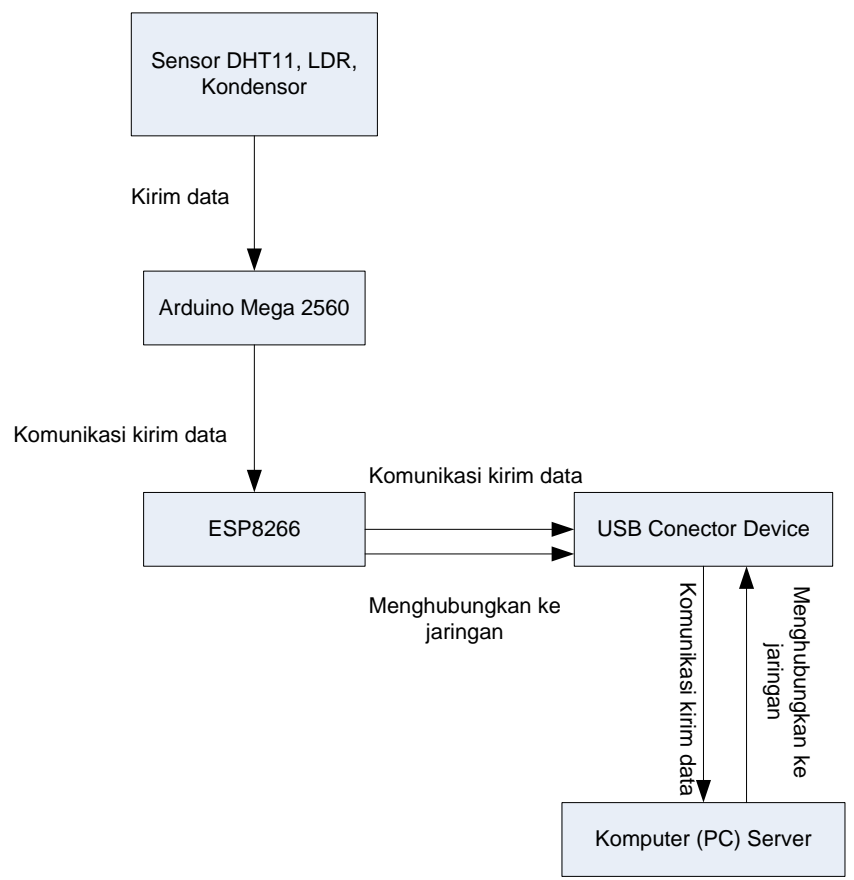

Gambar 3.6 Box diagram arsitektur perangkat keras

Untuk mempermudah perancangan perangkat keras, dilakukan perancangan arsitektur dengan pembuatan box diagram. Hal ini dilakukan mengetahui interkoneksi semua modul yang terdapat dalam sistem. Box diagram arsitektur perancangan perangkat keras yang dimaksud diperlihatkan pada gambar di atas.

\section{Hasil}

Menguraikan hasil dari penelitian yang telah dilakukan, berikut merupakan tampilan protoype alat yang telah dirakit berdasarkan rancangan yang dibuat sebelumnya.

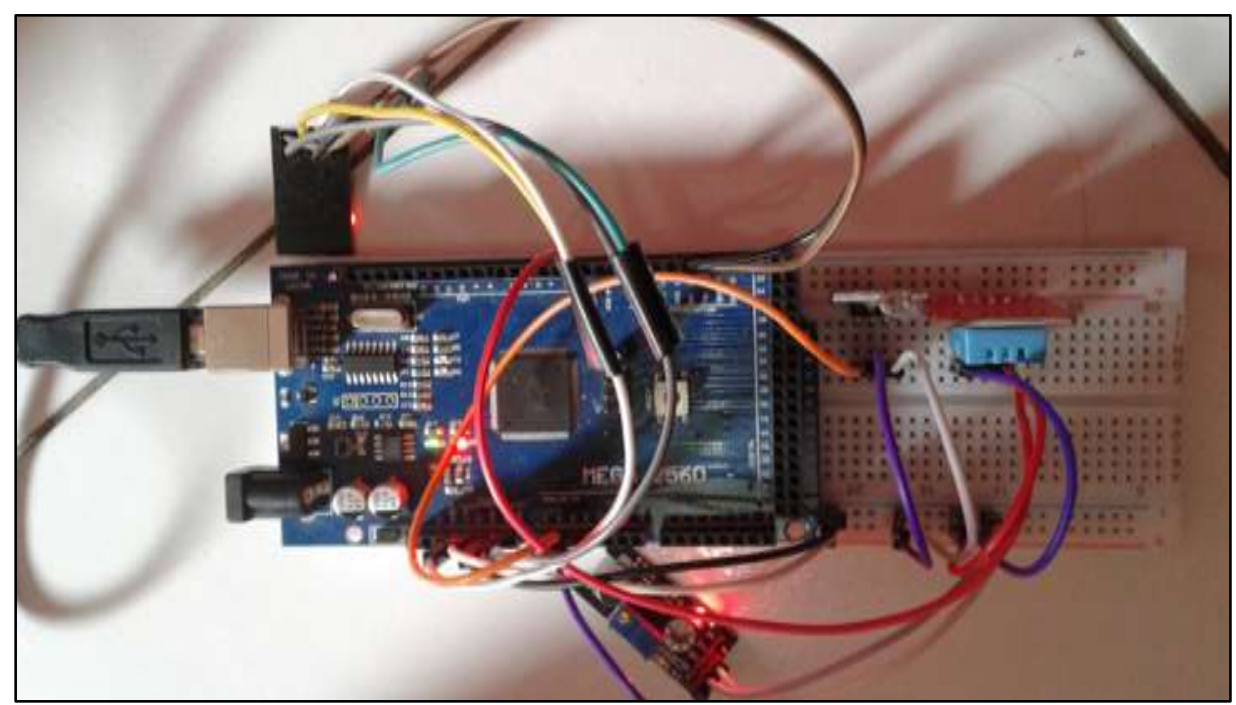

Gambar 4.18 Prototype Alat

Agar Arduino dan ESP8266 saling terhubung dan sensor dapat berfungsi sesuai dengan apa yang diinginkan, perlu adanya pemrograman pada board Arduino dan ESP8266, untuk proses kerja alat yang dibuat yaitu Arduino menerima data yang diperoleh dari sensor, kemudian data dikirimkan oleh Arduino 
ke ESP8266 yang dikoneksikan dengan jaringan, kemudian data dikirim oleh ESP8266 ke komputer server melalui jaringan. Pemrograman mikrokontroler menggunakan aplikasi Arduino IDE. Proses pemrograman Arduino Mega 2560 meliput proses pemrograman sensor DHT11, LDR dan Kondensor. Serta pemrograman untuk proses konfigurasi Arduino dengan ESP8266.

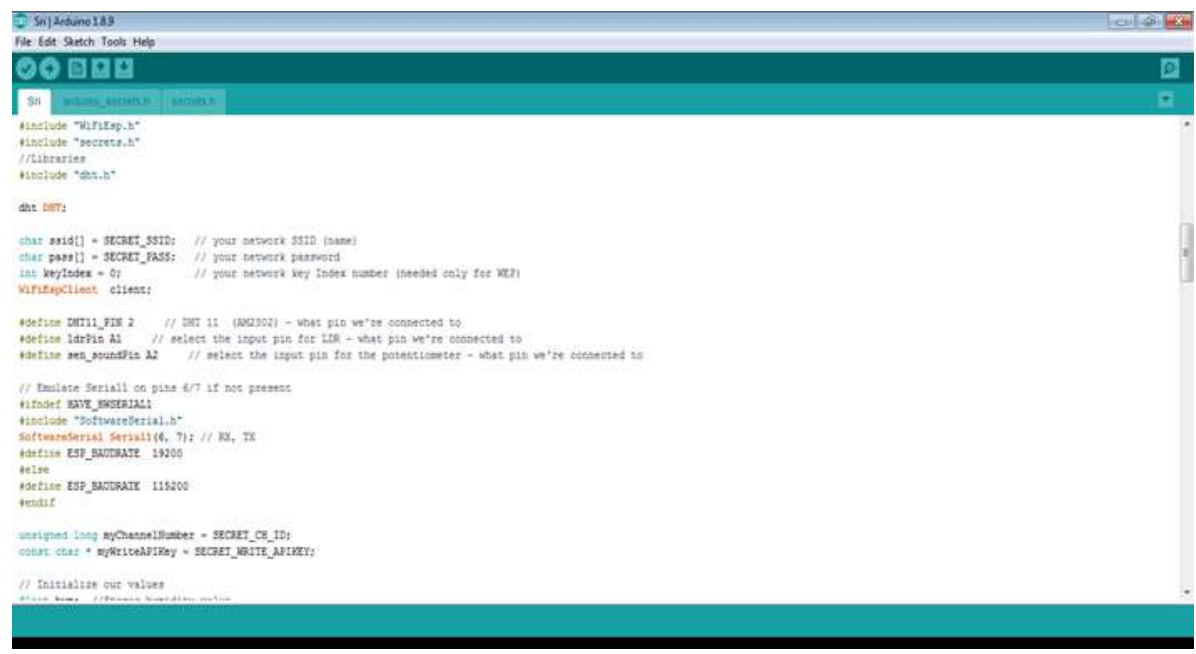

Gambar 4.19 Proses Pemrograman Arduino Mega 2560

Untuk proses pengujian dilakukan dengan menggabungkan sensor dan board mikrokontroler selanjutnya memprogram Arduino Mega 2560 dan ESP8266 menggunakan aplikasi Arduino IDE pada komputer.

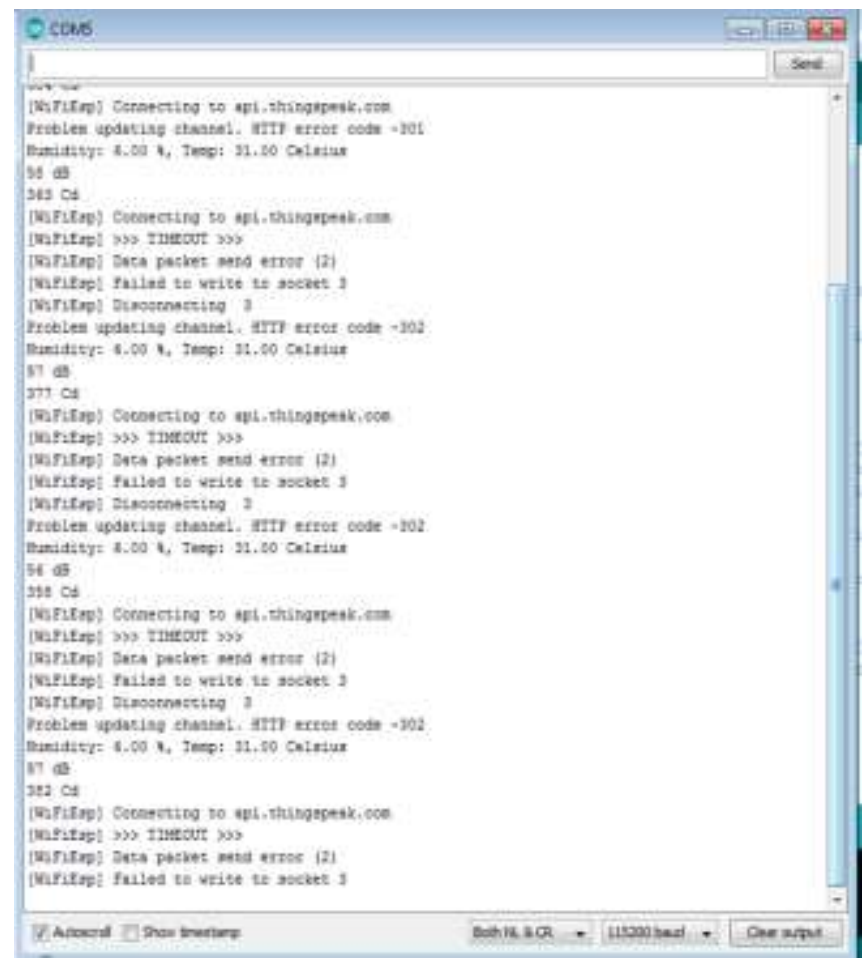

Gambar 4.20 Pengujian Alat menggunakan serial monitor 


\section{Kesimpulan}

Berdasarkan analisa perancangan sistem, implementasi, dan hasil pengujian sistem, maka dapat disimpulkan bahwa:

1. Sistem Cerdas Pemantau Kenyamanan Ruang Kelas Berbasis Internet Of Things (IoT) menggunakan Metode K-Means pada Platform Thingspeak yang penulis kerjakan telah berfungsi dengan baik sesuai dengan harapan.

2. Pengolahan data dengan menggunakan sensor DHT1, LDR, Kondensor sangat mempermudah pemrosesan data pada Arduino Mega 2560.

3. Sistem monitoring ruang kelas ini akan medeteksi perubahan kelembaban, suhu, suara, dan cahaya sekitar sensor, kemudian data diolah lewat mikrokontroler arduino mega 2560 yang terhubung dengan internet dengan bantuan ESP8266, data akan ditampilkan pada platform thingspeak, hasil data yang telah masuk pada thingspeak akan di export kemudian data akan dihitung menggunakan metode K-means.

4. Pengujian yang dilakukan dalam penelitian ini, iterasi clustering data terjadi sebanyak 3 kali iterasi.

5. Pengujian yang dilakukan ditemukan pusat cluster dengan Cluster $1=47,76 ; 26,07 ; 61 ; 92$; 3602 cluster $2=58 ; 29 ; 59,5 ; 502$ dan cluster $3=60 ; 30,25 ; 58,75 ; 769,75$.

\section{Daftar Pustaka}

[1] Sugini, "Pemaknaan istilah - istilah kualitas kenyamanan thermal ruang dalam kaitan dengan variabel iklim ruang," Jurnal Logika, vol. 1 No. 2, 2004.

[2] I. H. Witten, E. Frank and M. A. Hall, DATA MINING Practical Machine Learning Tools and Techniques 3rd Edition, Burlington, USA.: Morgan Kaufman, 2011.

[3] Chamim, Mikrokontroler Belajar Code Vision AVR Mulai Dari Nol., Yogyakarta: Graha Ilmu, 2012.

[4] K. Ashton, "Internet Of Things," RFID Journal, 2009.

[5] D. F. Parma, Desriyanti and M. Muhsin, "ALAT PENDETEKSI KENYAMANAN KELAS DENGAN SENSOR 3 IN 1 (CAHAYA, SUHU DAN SUARA) BESERTA AKSI KONTROL (LAMPU, AC DAN ALARM)," KOMPUTEK, vol. 2, 2018.

[6] H. Dhika and F. Destiawati, "Penerapan Internet Of Things dalam ruang kelas," Prosiding Diskusi Panel Unindra, vol. 1, 2017.

[7] Mardalius, "IMPLEMENTASI ALGORITMA K-MEANS CLUSTERING UNTUK MENENTUKAN KELAS KELOMPOK BIMBINGAN BELAJAR TAMBAHAN (STUDI KASUS : SISWA SMA NEGERI 1 RANAH PESISIR)," in SEMILOKA ROYAL, Kisaran Naga, 2017. 